\title{
MONITORING ATMOSPHERIC AEROSOLS OVER THE URMIA LAKE BY CALIPSO AND A GROUND BASED DEPOLARIZED LIDAR
}

\author{
Hamid R. Khalesifard ${ }^{1,2 *}$, Hossein Panahifar ${ }^{1}$, Fatemeh Ghomashi ${ }^{1}$, Salar Alizadeh ${ }^{1}$ and
}

\section{Ruhollah Moradhaseli ${ }^{3}$}

\section{${ }^{1}$ Department of Physics, and ${ }^{2}$ Research Center for Climate Change and Global Warming, Institute for Advanced Studies in Basic Sciences, Zanjan 4513766731, Iran \\ ${ }^{3}$ Physics Department, Faculty of Science, Zanjan Brach, Islamic Azad University, Zanjan, Iran *khalesi@iasbs.ac.ir}

\begin{abstract}
The Urmia Lake, a hypersaline lake in Northwest Iran is facing a severe drying scenario. We have installed an azimuthal scanning depolarized backscatter lidar in the coast of the lake to monitor the atmospheric aerosols that may originate from the dried lake bed. We also used the CALIPSO recordings to monitor the aerosol optical depth and particulate depolarization ratio just over the lake. Recordings of the lidar and CALIPSO both show that dry salt particles can be found in the atmospheric boundary layer over the lake especially in summer times. Also CALIPSO data in synergy with HYSPLIT model show that the lake is not an intense aerosol source comparing to neighboring sources like the Mesopotamia region but it is under their influence.
\end{abstract}

\section{INTRODUCTION}

The Urmia Lake (UL) in Northwest Iran (Figure 1) once was the second largest permanent hypersaline lake in the world. Now the lake is experiencing a serious drying challenge that has been started about twenty years ago. As a result of this environmental disaster, the water level of the lake has dropped significantly (Figure 2) in a way that its surface area has shrunk to just $12 \%$ of its value in 1995 [1]. Many reasons have been mentioned for the drought of the lake, including climate change [2,3] and human factors like building dams, digging too many wells and excessive use of water resources in the catchment area of the lake $[1,4-6]$. There is a debate that drying of the UL has turned it to an active source of salt or mineral particles [7]. In this work we are trying to find the types of the particles that may originate from the dried lake bed and investigate how active is the UL as a source for such particles. On doing this we have

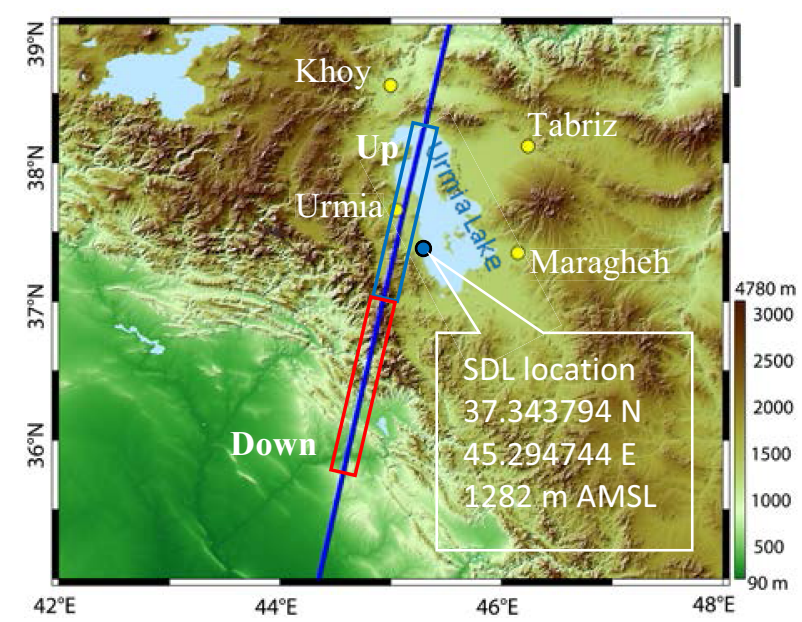

Figure 1 Orographic map of the Urmia Lake water catchment area in Northwest Iran and a night-time CALIPSO ground track over it. Blue spot at the west coast of the lake is the location of the installed lidar.

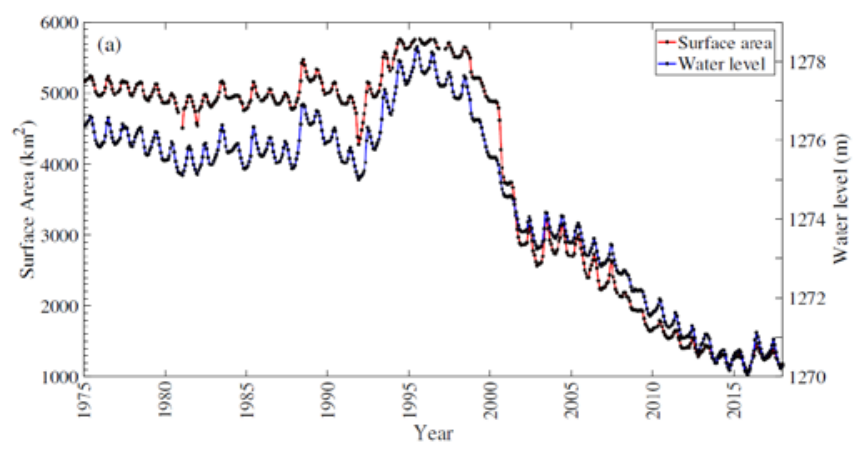

Figure 2 Variations of surface area and water level height of the Urmia Lake from 1975 to 2017.

used the recordings of the CALIPSO satellite over the UL since its launching time and a scanning depolarized elastic backscatter lidar (SDL) that we have installed at the western coast of the UL to monitor the atmospheric aerosols just in the vicinity of the lake. We are expecting that comparison of aerosol optical depth (AOD) and particulate depolarization ratio (PDR) from CALIPSO with SDL measurements on similar 
parameters provides trustable tools to specify the atmospheric aerosols in the water catchment area of the UL and gives us an estimation about the activities of the UL as a source of atmospheric aerosols

\section{METHODOLOGY}

\subsection{CALIPSO recordings}

Figure 1 illustrates a nighttime CALIPSO ground track that is passing almost over the northern half of the UL. To compare the atmospheric particles inside the water catchment area of the lake with those that maybe found outside of it, the track is divided in two segments, Up and Down. The Up segment is almost inside the water catchment area but Down is outside of it and under the influence of dust events that are originating from the Mesopotamian region [8, 9]. To investigate the atmospheric aerosols over the mentioned segments, CALIPSO level 2 aerosol products have been used to extract AOD and PDR for atmospheric aerosols in these regions. The data set covers June 2006 to December 2017. Since the crest line of the surrounding mountains around the water catchment varies between $2000 \mathrm{~m}$ above mean sea level (amsl) to $3500 \mathrm{~m}$ amsl, the investigation has been carried out at two altitude regimes: i.e. altitudes from surface up to $2000 \mathrm{~m}$ amsl and altitudes higher than $3000 \mathrm{~m}$ amsl. From now on we label these two altitude regimes by letters $l$ and $h$.

\subsection{The scanning depolarized backscatter lidar, SDL}

The SDL has a frequency doubled $10 \mathrm{~ns}$ pulsed Nd-YAG laser and a 5x beam expander as its transmitter. The laser has an energy of 100 (150) $\mathrm{mJ} /$ pulse at $532(1064) \mathrm{nm}$. At the receiver, an 8" Cassegrain telescope collects the backscattered lights and then signals are recorded at $532 \mathrm{~nm}$ in parallel and perpendicular polarizations respect to that of the laser beam (Figure 3a). The scanning scheme of the SDL is shown in Figure $3 b$. The azimuthal angle, $\varphi$, varies between $0^{\circ}$ to $180^{\circ}$ in steps of $1.0^{\circ} \pm 0.1^{\circ}$ degree by means of a stepper motor through a $1 / 90$ reducing speed gear box. The elevation angle, $\theta$, varies between $45^{\circ}$ to $90^{\circ}$ $\left( \pm 0.1^{\circ}\right)$ continuously by means of a hand hold screw. The SDL also can aim the zenith direction $\left(\theta=0^{\circ}\right)$. The spatial resolution of the lidar
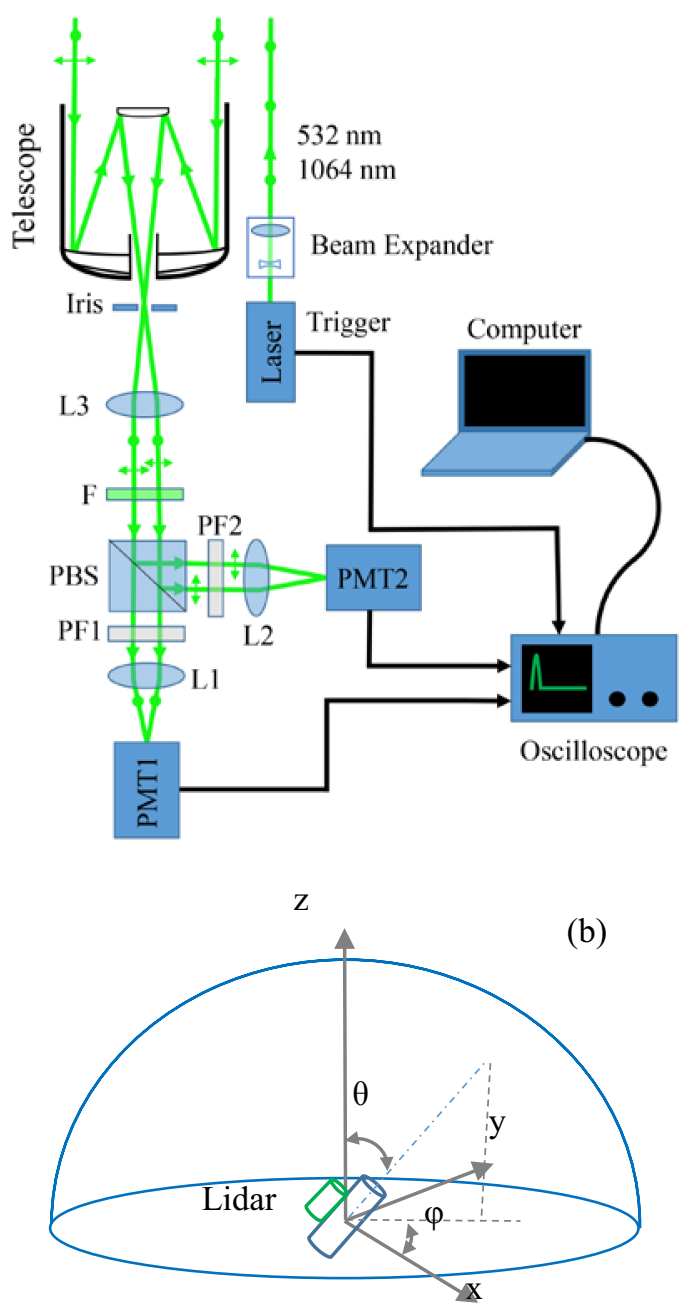

Figure 3 a) Optical setup of SDL; L-lens, PBSpolarizing beam splitter, PF-polarizing filter, b) the scanning scheme of SDL

signals is $12 \mathrm{~m}$ and its range is $12 \mathrm{~km}$ in zenith direction.

\section{RESULTS AND DISCUSSIONS}

\subsection{CALIPSO recordings}

Figure 4 shows variations of the aerosol layer height, $h_{\text {layer, }}$ versus the aerosol layer optical depth, $\tau_{\text {layer, }}$ over Up and Down segments, obtained from the CALIPSO recordings. As the figure shows, the aerosol layers over the Up segment appear at higher altitudes. This can be seen more clearly, when an average would be performed over all recorded layer heights $\tau_{\text {layer }} \geq 0.2$. Dashed black (red) lines in Figure 4 depict this value for Up (Down) segment as $3.1(2.5) \mathrm{km}$. In other words, aerosol layers over the UL mostly 


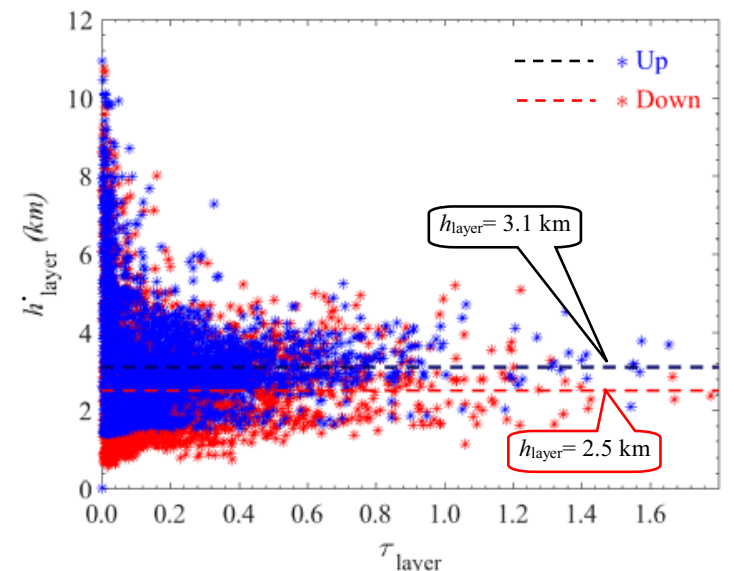

Figure 4 Variations of $h_{\text {layer, }}$, versus $\tau$ layer, over Up and Down segments. Black (red) dashed lines corresponds to average height of the aerosol layers with $\tau_{\text {layer }} \geq 0.2$ for Up (Down) segment.

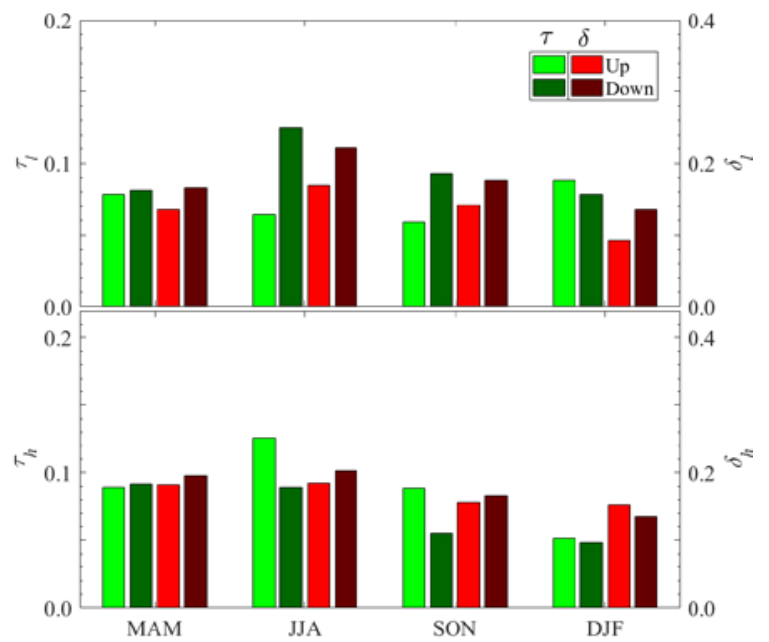

Figure 5 Seasonal variations of AOD and PDR over Up and Down segments, CALIPSO recordings, Jun. 2007 to Dec. 2017 , a) and b) $l$ and $h$ altitude regimes.

are appearing above the crest lines of the mountains around the UL water catchment area. It is also interesting to look at seasonal variations of AOD and PDR over Up and Down segments for $l$ and $h$ altitude-regimes. These variations are shown in Figure 5a and 5b. As Figure 5a shows higher values of the AOD for altitudes lower than $2 \mathrm{~km}$ amsl, $\tau_{l}$, in the Up (Down) segment are happening in winter (summer) times when the PDR, $\delta_{l}$, has its lowest (highest) values. But for altitudes higher than $3.0 \mathrm{~km}$, Figure $5 \mathrm{~b}$ shows more or less similar behaviors for Up and Down segments. In other words, one can conclude that the water catchment area of the UL, like other regions in Northwest Iran, is very much under the influence of dust sources in its west and east sides, i.e. Mesopotamia and the dry region between the Caspian Sea and Aral Lake [8, 10]. This means that referring to such recordings, it is not easy to find the UL as an influencing source of mineral particles for the regions outside of its water catchment area.

\subsection{SDL recordings}

Since October 2018, the SDL has been installed at the western coast of the UL (37.343794 N, 45.294744 E, $1282 \mathrm{~m}$ AMSL) in Rashakan preserved area (Figure 1). Just before start of the first precipitations in October, when the lake bed in the vicinity of the installation site was quite dry, we performed few azimuthal scans ( $\varphi$-scan in Figure $3 \mathrm{~b}$ ) at different $\theta$ values (Figure $3 \mathrm{~b}$ ). The scanning calibration of the lidar is in the way that, when $\varphi=0$, the lidar is just aiming the east. Figure 6 shows a recorded SDL scan at 11:30 UTC on 01 Oct. 2018, where $\varphi$ is scanned from $-70^{\circ}$ to $70^{\circ}$ and $\theta$ is set at $40^{\circ}$.
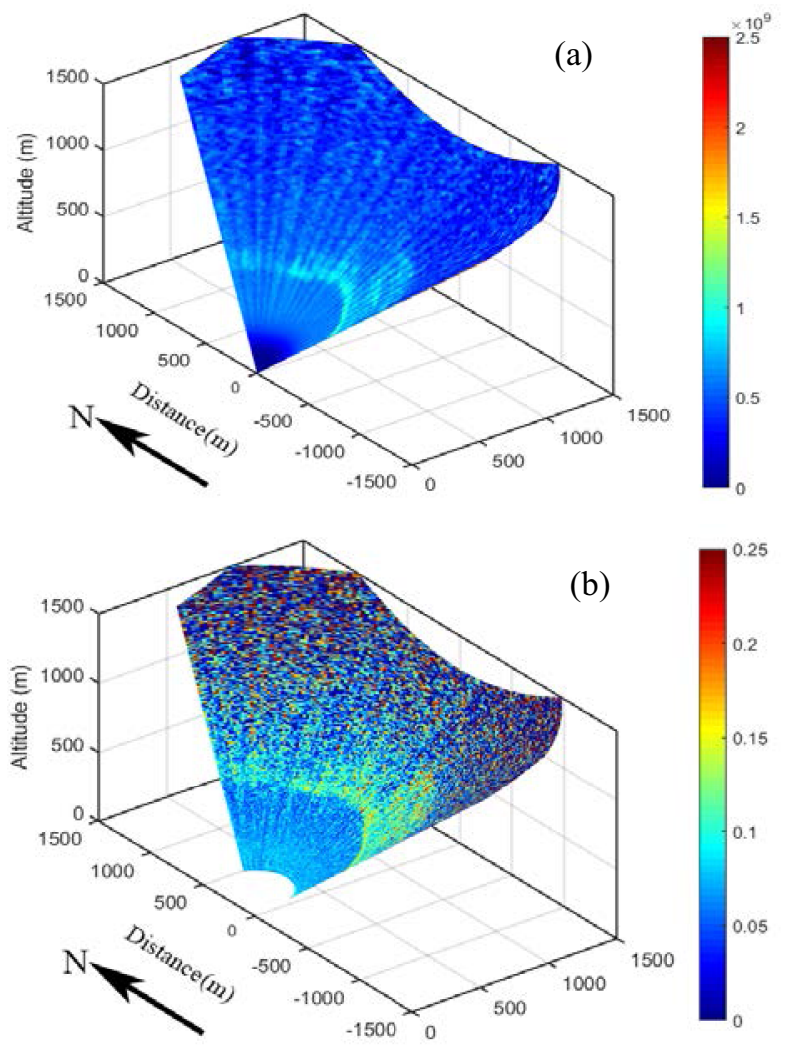

Figure 6 SDL signals for an azimuthal scan, $\varphi=-70^{\circ}$ to $\varphi=70^{\circ}$ and $\theta=40^{\circ}, 11: 30$ UTC, 01 Oct. 2018, a) range corrected backscatter signals on parallel channel, b) depolarization ratio. 
Figure 6a shows the range corrected lidar signals on parallel channel. An aerosol layer that is extending from $400 \mathrm{~m}$ to $800 \mathrm{~m}$ agl can be seen in this figure. Figure $6 \mathrm{~b}$ depicts depolarization for this scan. Figure $6 \mathrm{~b}$ shows that the depolarization ratio for this layer ranges from 0.1 to 0.15 . This is in agreement with previous report on depolarization associated with dry salt particles [11]. It also confirms our previous work on monitoring the depolarization of dust layers in vicinity of the UL by CALIPSO recordings where we found it as: $0.16 \pm 0.05$ [12]. HYSPLIT backward trajectories in Figure 7 show that the aerosol layer in Figure 6 is originated from a local source, i.e. the Urmia Lake. Recoded time series of SDL in zenith direction during December 2018 (not shown here) also show similar or lower depolarization values for surface atmospheric layers. Considerable reduction of the depolarization at these time can be due to existence of anthropogenic particles.

\section{CONCLUSION}

We have used the recordings by the space lidar onboard the CALIPSO satellite and a ground based scanning backscatter depolarized lidar to investigate the type of atmospheric aerosols that may originate from the dried bed of the Urmia Lake. CALIPSO recordings on AOD and PDR don't show that the UL is an intense source of atmospheric aerosols for its water catchment area and outside of it. However, these recording

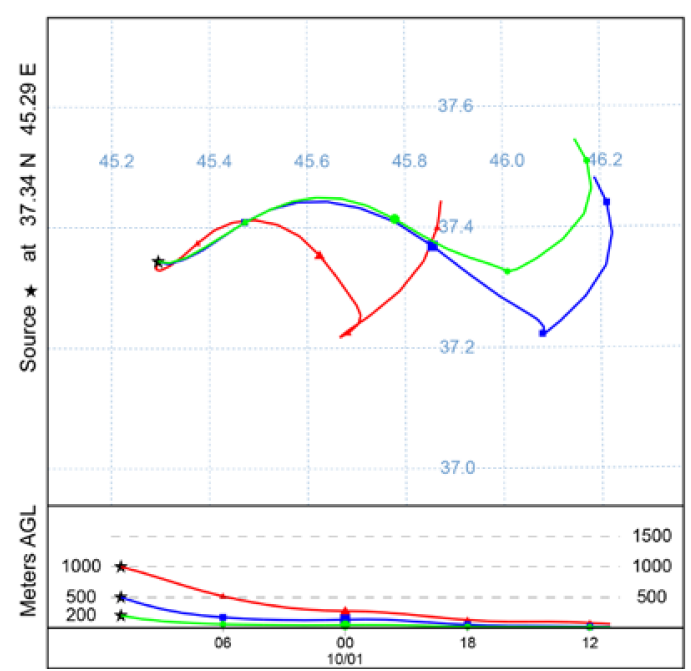

Figure 7 NOAA HYSPLIT backward trajectories ending in Rashakan, at 11:00 UTC, Oct. 01, 2018 indicate that the UL and its surrounding are under the influence of neighboring dust sources like Mesopotamia, especially during dry months of the year. These also show that during winter times the water catchment area of the UL mostly is contaminated with urban industrial particles. On the other side, SDL measurements over the UL are indicating that atmospheric aerosols that may be raised from the dried lake bed, mostly are dry salt particles

\section{ACKNOWLEDGEMENTS}

This work was supported by Urmia Lake Restoration Program (ULRP) under Grant No. 96100201. The authors appreciate the NASA Langley Research Center for providing the CALIPSO data. We are also grateful to the NOAA Air Resources Laboratory (ARL) for the provision of the HYSPLIT transport model.

\section{REFERENCES}

[1] A. AghaKouchak, et al. Journal of Great Lakes Research 41 (1), 307-311 (2015).

[2] M. Abbaspour, et al. International Journal of Environmental Science and Technology 9 (2), 257-266 (2012).

[3] A. Delju, et al. Theoretical and applied climatology 111 (1-2), 285-296 (2013).

[4] F. Fathian, et al. Theoretical and Applied Climatology 119 (3-4), 443-464 (2015).

[5] E. Hassanzadeh, et al. Water Resources Management 26 (1), 129-145 (2012).

[6] A. Taravat, et al. Water 8 (11), 478 (2016).

[7] P. Ginoux, et al. Reviews of Geophysics 50 (3) (2012).

[8] F. Abdi Vishkaee, et al. Journal of Geophysical Research: Atmospheres 116 (D5) (2011).

[9] A. Masoumi, et al. Atmospheric research 120, 343-355 (2013).

[10] F. Abdi Vishkaee, et al. Journal of Geophysical Research: Atmospheres 117 (D3) (2012).

[11] M. Haarig, et al. Atmospheric Chemistry and Physics 17 (23), 14199 (2017).

[12] F. Ghomashi and H. Khalesifard, to be appear in Centeral Asian dust conferece (Dushanbeh, Tajikistan, 2019). 